\title{
PROBLEMS FACED BY THE SMALL SCALE DAIRY OWNERS IN RECEIVING VETERINARY SERVICES IN SELECTED AREAS OF CHITTAGONG
}

\author{
M. A. Imtiaz ${ }^{1 *}$ and S. Rana ${ }^{2}$ \\ ${ }^{1}$ Department of Physiology, Biochemistry and Pharmacology; ${ }^{2}$ Department of Agricultural Economics and Social \\ Sciences, Chittagong Veterinary and Animal Sciences University, Khulshi-4225, Chittagong, Bangladesh
}

\begin{abstract}
This study investigated the problems faced by the small scale dairy owners in receiving veterinary services in selected areas of Chittagong (Chittagong metropolitan area, Sitakunda and Patiya Upazila). A pre-tested structured questionnaire data were collected from a sample of 45 farmers during November 2012 to January 2013. A four (0-3) point rating scale was used to evaluate the constraint as high (3), moderate (2), low (1) and absence of any constraint (0). The highest ranking constraint was unavailability of veterinarian in the farm area with higher service charge on specialist doctor followed by no emergency doorstep services, poor services in local veterinary hospital, ineffectiveness at artificial insemination, high cost for drugs and vaccines and lack of illiteracy among the livestock owners These findings will help to redesign and rectify the condition of present veterinary constraints in selected areas of Chittagong, Bangladesh.
\end{abstract}

Key words: Small scale dairy owners, Chittagonj, veterinary services

\section{INTRODUCTION}

Dairying is the mixed farming system in Bangladesh and it is a strong tool to develop the micro-economy in villages (Saadullah, 2001). Dairying is also considered a strong tool to develop a village micro economy of Bangladesh (Shamsuddin et al., 2007) in order to improve rural livelihoods and to alleviate rural poverty. Most of the cattle in Bangladesh are non-descriptive, low yielding and few crossbred with Shahiwal, Red Chittagong and Pabna cattle. High yielding crossbred like Jersey and Holstein-Friesian are found in commercial level. About $64 \%$ of milk in Bangladesh comes from dairy cattle (FAO, 2004).

In Bangladesh, dairying is growing faster; but it also faces lots of problems of high input and low output prices. The condition leads to lower profitability in dairy farming. Diseases, along with non-availability of feed resources and nutrition are the most important constraints to milk production. In Bangladesh, the government, co-operatives, private sectors and a few non-governmental organizations (NGOs) provide veterinary services and artificial insemination facilities to the dairy farmers. However it is well known that the quality of the veterinary services provided by public sector institution is poor and those institutions providing these services are highly insufficient. Therefore, there is a need to re-structure and re-orient the veterinary services with breeding services as well as extension services.

Inadequate veterinary services are one of the major obstacles for livestock development in Bangladesh. The ratio of Veterinary Surgeons to farm animals and birds was estimated at I: 1.7 million and only $15-20 \%$ of farm animals receive routine vaccination. Private sector investment in the animal health sector remains low and is expanding gradually (Bangladesh National Livestock Development Policy, 2007).

Animal health service is important for maintaining good productivity of animals. Diseases are the major constraint to dairy production in Bangladesh; the extent of losses due to disease is very high. It is understood that most of the small scale dairy owners do not obtain proper animal health services. Therefore the study was undertaken in order to have an understanding of the above-mentioned issue with the objective of identifying the specific problems faced by them.

\section{MATERIALS AND METHODS}

\section{Study area}

The study was carried out in three selected areas of Chittagong district (Chittagong Metropolitan Area, Sitakunda and Patiya Upazila). These areas were selected purposively due to fast growing of small scale dairy farming.

*Corresponding e-mail address: ashif.shawn@gmail.com 


\section{A. Imtiaz and S. Rana}

\section{Population and Sampling}

On a dairy farm, having 10-12 cows was considered to be the population of the study. A sample of 45 small dairy farmers was randomly selected (15 from each three specific location) from the entire population.

\section{Research Instrument}

A pre-tested structured questionnaire was used to collect relevant information. Focus Group Discussion (FGD) and observation was also conducted to verify and cross check the information collected through personal interview.

\section{Measurement of focus variable of the study}

The focus variable of the study was problems faced by the small scale dairy owners in getting veterinary services. A 4-point ratting scale was used to measure the variable. Different problems were identified through discussion with the key personnel. A respondent was asked to indicate whether she/he faced "high constraint", "moderate constraint", "low constraint" or "no constraint" against each constraint items and scores were assigned for those responses as 3, 2, 1 and 0 respectively (Rahman and Rana, 2013). To have a comprehensive idea about the extent of the problems and to compare among the selected constraint items the mean constraint score was computed.

\section{Data Collection and Management}

Data were collected during the period from November 2012 to January 2013 using above mentioned instruments. SPSS (Statistical Package for Social Science) software was used for data management and analysis.

\section{RESULTS AND DISCUSSION}

Data tabulated in Table shows that small scale dairy owner in Chittagong Metropolitan Area (CMA) having less constraint in receiving veterinary services compared to other two areas of the study. It is due to availability of more facilities in CMA like veterinary hospitals, AI centre, Specialist veterinarian, university and private clinics.

Table 1. Problems faced by the small scale dairy owner in receiving veterinary services in selected areas of Chittagong.

\begin{tabular}{|c|c|c|c|c|c|}
\hline \multirow{2}{*}{$\begin{array}{l}\text { Sl. } \\
\text { No. }\end{array}$} & \multirow[t]{2}{*}{ Problem items } & \multicolumn{4}{|c|}{ Mean problem score ( range: $0-3$ ) } \\
\hline & & Overall & Patiya & Sitakunda & CMA \\
\hline 1 & Veterinarians are not available in the locality & 1.04 & 1.19 & 1.08 & 0.43 \\
\hline 2 & In emergency cases, no doorstep service provided by DLS & 1.33 & 1.42 & 1.42 & 0.86 \\
\hline 3 & $\begin{array}{l}\text { Insufficient services (timely attention, careful attitude etc.) in } \\
\text { hospital }\end{array}$ & 2.31 & 2.46 & 2.42 & 1.57 \\
\hline 4 & Lack of AI services in the veterinary hospitals & 1.11 & 1.15 & 1.08 & 1.00 \\
\hline 5 & Service from ULO/VS/Specialist doctor expensive & 2.53 & 2.65 & 2.50 & 2.14 \\
\hline 6 & Shortage of medicine and vaccines in veterinary hospitals & 2.78 & 2.88 & 2.83 & 2.29 \\
\hline 7 & $\begin{array}{l}\text { Ineffectiveness of artificial insemination from the veterinary } \\
\text { hospitals }\end{array}$ & 1.64 & 1.96 & 1.25 & 1.14 \\
\hline 8 & $\begin{array}{l}\text { Lack of understanding by the owners on severity of problem in } \\
\text { livestock (necessity of treatment) }\end{array}$ & 1.76 & 1.92 & 1.67 & 1.29 \\
\hline 9 & Lack of training on livestock & 1.82 & 1.92 & 2.00 & 1.14 \\
\hline
\end{tabular}

$\mathrm{CMA}=$ Chittagong Metropolitan Area, ULO= Upazilla Livestock Officer, VS= Veterinary Surgeon

It revealed that majority of the constraint items related with veterinary hospitals and cost involvement faced by the small scale dairy owners were very high (indicated by mean value). Thus, these constraints items could beconsidered as the major barriers to the development of dairy entrepreneurship in that area. The major problems are mainly related to availability of veterinarians in the locality as well as door step services by the DLS, high cost of medicines and services from specialist doctors and shortage of veterinary services at hospitals. It was observed that respondent who received training earlier in any aspects of livestock rearing and has access to media and information they face less problems in receiving veterinary services than others. 
Majority of the respondents think that establishment of a veterinary hospital in their locality and increasing the number of doctors in existing veterinary hospitals can solve these problems. They also give their opinion to enhance the door step services of DLS.

The result is supported by some other studies conducted in India which showed that veterinary services were not easily available to rural areas (Kokate and Tyagi, 1991; Singh, 1995). In Bangladesh context, according to Rabbani et al. (2004), the dairy farm owners of some selected areas of Bogra district mentioned that inadequate veterinary services was a major problem for dairy enterprise development.

\section{CONCLUSION}

Based on the findings, it could be concluded that veterinary hospital related problems were in higher extent faced by the small scale dairy owners. However in case of emergency they mostly depend on veterinary hospitals of DLS. High input cost like medicine, vaccines etc. was one of the major problem due to not getting proper material support from government veterinary hospitals. Most the problems could be solved through strengthening upazilla veterinary hospitals with proper material and technical support by the government and also establishing private veterinary clinics.

\section{REFERENCES}

1. Bangladesh National Livestock Development Policy (2007). Ministry of Fisheries and Livestock, Govt. of the People's Republic of Bangladesh, Dhaka.

2. FAO (2004). Production Year Book. Rome, Italy.

3. Kokate KD and Tyagi KC (1991). Dairy farming practices of tribal cattle owners. Indian Journal of Extension Education 70-75.

4. Rabbani MS, Alam MM, Ali MY, Rahman SMR and Saha BK (2004). Participation of rural people in dairy enterprise in a selected area of Bangladesh. Pakistan Journal of Nutrition 3(1): 29-34.

5. Rahman MH and Rana S (2013). Farmer's constraints in receiving animal health services in rural areas of Bangladesh. Bangladesh Journal of Veterinary and Animal Sciences 2:21-27.

6. Saadullah M (2001). Smallholder Dairy Production and Marketing in Bangladesh. A paper presented at SouthSouth Workshop on Smallholder Dairy Production and Marketing. NDDB-ILBS, 13-16, March, 2001, Ahmedabad, India.

7. Shamsuddin M, Alam MM, Hossein MS, Goodger WJ, Bari FY, Ahmed TU, Hossain MM and Khan AHMSI (2007). Participatory rural appraisal to identify needs and prospects of market-oriented dairy industries in Bangladesh. Tropical Animal Health and Production 39:567-581.

8. Singh L (1995). Participation in rural women in dairy task in Nadia and South 24 Parganas of West Bengal. Indian Journal of Dairy Science 48:285-289. 